\title{
Transformation-Induced Creep Recovery of TiNi Shape Memory Alloy in Subloop Loading
}

\author{
Fumiki MORI ${ }^{1}$, Kohei TAKEDA ${ }^{2 *}$ \\ ${ }^{1}$ Department of Mechanical Engineering, Graduate School of Engineering, Aichi Institute of Technology, 1247, Yachigusa, \\ Yakusa-cho, Toyota-city, Aichi Japan \\ ${ }^{2}$ Department of Mechanical Engineering, Aichi Institute of Technology, 1247, Yachigusa, Yakusa-cho, Toyota-city, Aichi Japan \\ *k-takeda@aitech.ac.jp
}

Introduction. Shape memory alloy (SMA) has activated the research on smart materials and structures due to a unique characteristics of shape memory effect and superelasticity based on the martensitic and the reverse transformation. In this study, transformationinduced creep recovery (TICR) of TiNi SNA under constant stress in subloop is considered for the practical application. In particular, the behavior of a transformation band that appeared on specimen surface in TICR was investigated. The TICR occurs due to small temperature change and the reverse transformation band progresses after unloading followed by holding constant stress, then the strain recovers to $1 \%$.

Experimental conditions. The specimen was TiNi SMA tape with composition of Ti-50.95at $\% \mathrm{Ni}$ manufactured by Furukawa Techno Material Co., Ltd., which exhibits superelasticity at room temperature. The thickness and width were $0.38 \mathrm{~mm}$ and $10.3 \mathrm{~mm}$, respectively. The gage length was $100 \mathrm{~mm}$. The TISR test was conducted under a strain rate of $1 \times 10^{-4} / \mathrm{s}$ till strain of $8 \%$ in loading process. Then, the strain of $8 \%$ was held for cooling. In unloading process, the stress rate $d \sigma / d t$ was $-5 \mathrm{MPa} / \mathrm{s}$ from $8 \%$ to $6 \%$ strain as stressholding start strain. During holding stress, the

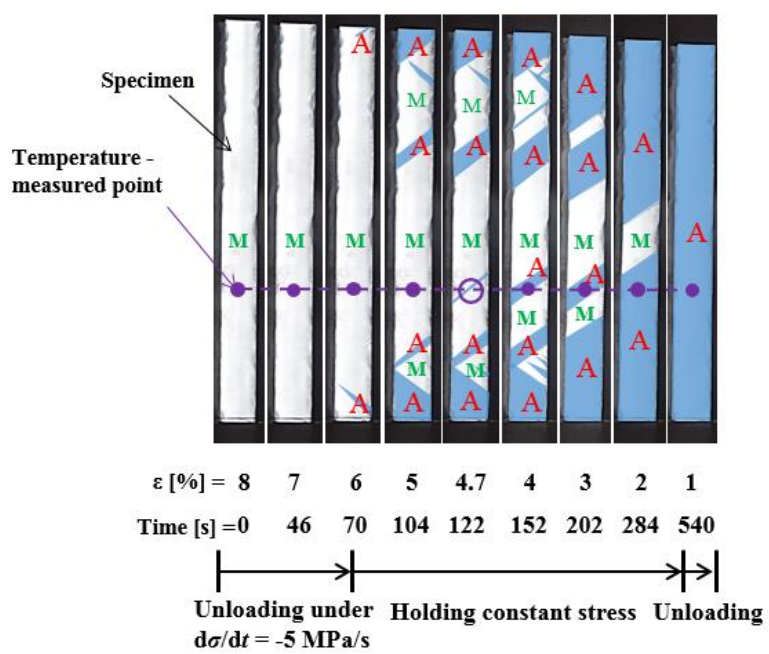

Fig. 1 Photographs of specimen surface at various strain in unloading process of the TICR test under stress rate of $-5 \mathrm{MPa} / \mathrm{s}$ followed by holding constant stress from the strain of $6 \%$. transformation band and local temperature were observed by the digital camera and the infrared thermography, respectively.

Transformation band behavior. Figure 1 shows the progress of the transformation band in holding constant stress after unloading under a stress rate of $-5 \mathrm{MPa} / \mathrm{s}$. The austenitic phase region of the specimen surface in Fig. 1 is colored in blue, and the martensitic phase is denoted by "M" and the austenitic phase by "A". In Fig. 1 , the initial phase of specimen at unloading-start strain of $8 \%$ is martensite. At strain of $6 \%$, the reverse transformation band appears at lower place of specimen. During holding constant stress, another band occurs at the upper place. Then strain decreases due to these transformation bands expanding.

Local temperature change in creep recovery. Figure 2 shows the local temperature change $\Delta T$ between the location of the marked point on the specimen surface in Fig. 1 and the ambient temperature. In Fig. 2, the temperature decreases in unloading under stress rate of $-5 \mathrm{MPa} / \mathrm{s}$ till strain of $6 \%$. After that the temperature increases due to heat exchange with ambient air. Then the new transformation band appears at the marked point of $4.7 \%$ strain in Fig. 1 due to the increasing temperature. In this moment, the temperature drops rapidly due to the endothermic reaction of reverse transformation as shown in Fig. 2. It can be seen that the temperature of the specimen is maintained during the transformation band progressing.

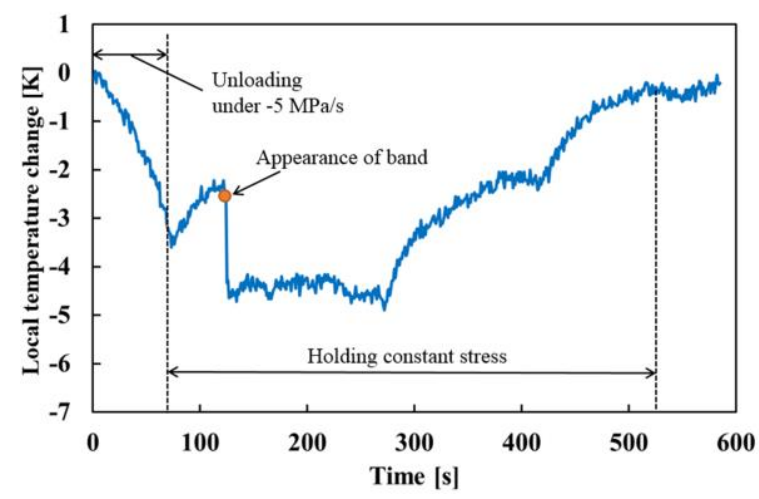

Fig. 2 Local temperature change in creep recovery during holding constant stress 